Compared to C-GCA, patients with large vessel involvement (LV-GCA and LV-CGCA) were younger and more frequently women, and the difference was further significant for patients with isolated LV-GCA. Patients with isolated LV-GCA had also the longer duration of symptoms at GCA diagnosis [LV-GCA 20(16-82) vs LV-C-GCA 12(4-16) vs C-GCA 4(3-12) weeks; $p<0.001]$. Systemic symptoms, as fever and fatigue, were associated with large vessel involvement, both in LV-GCA and LV-C-GCA groups. Polymyalgia rheumatica was equally reported in all three cohorts of patients and no significant differences were found in inflammatory markers levels according to vessel involvement.

In patients with large vessels involvement (LV-GCA and LV-C-GCA) thoracic aorta, subclavian arteries and abdominal aorta were the most frequently involved arteries.

Conclusion: GCA is not a single entity but includes several patterns of disease. Female gender, younger age and systemic symptoms are associated with large vessel involvement, regardless the presence or absence of cranial symptoms. The different clinical manifestations of large vessel GCA lead to a longer time to diagnosis if compared to C-GCA. For these reasons, in patients with the aforementioned characteristics, a large vessel involvement should be considered in order to reduce the time to diagnosis.

REFERENCES:

[1] De Boysson H, et al. Clin Exp Rheumatol 2019.

[2] Prieto-González S, et al. Ann Rheum Dis 2012.

[3] Brack A, et al. Arthritis Rheum 1999

[4] Muratore F, et al. Rheumatol 2015.

\begin{tabular}{|c|c|c|c|c|c|}
\hline & $\begin{array}{c}\text { GCA } \\
(n: 100)\end{array}$ & $\begin{array}{l}\text { C-GCA } \\
\text { (n: 61) }\end{array}$ & $\begin{array}{c}\text { LV-C-GCA } \\
(\mathrm{n}: 23)\end{array}$ & $\begin{array}{c}\text { LV-GCA } \\
\text { (n: 16) }\end{array}$ & $\mathrm{p}$ \\
\hline Age: median (IQR) & $76(67-79)$ & $75(71-80)$ & $74(69-77)$ & $63(59-72)$ & 0.001 \\
\hline \multirow[t]{2}{*}{ Female/ Male } & $68(68 \%) /$ & $\begin{array}{l}38(62 \%) / \\
23(38 \%)\end{array}$ & $17(74 \%) /$ & $13(81 \%) /$ & 0.276 \\
\hline & $32(32 \%)$ & & $6(26 \%)$ & $3(19 \%)$ & \\
\hline $\begin{array}{l}\text { Time between symptom onset and } \\
\text { diagnosis (weeks) }\end{array}$ & $8(4-20)$ & $4(3-12)$ & $12(4-16)$ & $20(16-82)$ & $<0.001$ \\
\hline Cranial symptoms (overall) & $84(84 \%)$ & $61(100 \%)$ & $23(100 \%)$ & $0(0 \%)$ & $<0.001$ \\
\hline New temporal headache & $77(77 \%)$ & $58(95 \%)$ & $19(83 \%)$ & $0(0 \%)$ & $<0.001$ \\
\hline Visual symptoms & $39(39 \%)$ & $34(56 \%)$ & $5(22 \%)$ & $0(0 \%)$ & $<0.001$ \\
\hline Jaw or tongue claudication & $35(35 \%)$ & $27(44 \%)$ & $8(35 \%)$ & $0(0 \%)$ & 0.004 \\
\hline Fever & $48(48 \%)$ & $23(38 \%)$ & $14(61 \%)$ & $11(69 \%)$ & 0.032 \\
\hline Fatigue & $75(75 \%)$ & $40(66 \%)$ & $21(91 \%)$ & $14(88 \%)$ & 0.023 \\
\hline Weight loss & $52(52 \%)$ & $28(46 \%)$ & $13(57 \%)$ & $11(69 \%)$ & 0.235 \\
\hline Polymyalgia rheumatica & $43(43 \%)$ & $27(44 \%)$ & $13(57 \%)$ & $3(19 \%)$ & 0.061 \\
\hline Arm or leg claudication & $5(5 \%)$ & $0(0 \%)$ & $4(17 \%)$ & $1(6 \%)$ & 0.005 \\
\hline CRP (C-reactive protein) & $83(45-127)$ & 77 (39-115) & $89(50-134)$ & ) $95(20-124)$ & 0.461 \\
\hline $\begin{array}{l}\text { ESR (erythrocyte sedimentation } \\
\text { rate) }\end{array}$ & $72(47-96)$ & $70(46-88)$ & $75(28-105)$ & $66(44-91)$ & 0.711 \\
\hline Cranial arteries & \%) & $0 \%)$ & 23 & 0 & $<0.001$ \\
\hline Carotid arteries & $19(19 \%)$ & $0(0 \%)$ & $12(52 \%)$ & $7(44 \%)$ & $<0.001$ \\
\hline Subclavian and upper limb arteries & s $21(21 \%)$ & $0(0 \%)$ & 10 (43\%) & $11(69 \%)$ & $<0.001$ \\
\hline Thoracic aorta & $29(29 \%)$ & $0(0 \%)$ & $15(65 \%)$ & $14(88 \%)$ & $<0.001$ \\
\hline Abdominal aorta & $21(21 \%)$ & $0(0 \%)$ & $10(43 \%)$ & $11(69 \%)$ & $<0.001$ \\
\hline Iliac and inferior limb arteries & $10(10 \%)$ & $0(0 \%)$ & $6(26 \%)$ & $4(25 \%)$ & $<0.001$ \\
\hline
\end{tabular}

Disclosure of Interests: None declared

DOI: 10.1136/annrheumdis-2021-eular.510

\section{POS0798 \\ GIANT CELL ARTERITIS TREATMENT PATTERNS AND RATES OF SERIOUS INFECTIONS}

S. Tedeschi ${ }^{1}$, Y. Jin ${ }^{2}$, S. Vine ${ }^{2}$, H. Lee ${ }^{2}$, A. Pethoe-Schramm ${ }^{3}$, V. Yau ${ }^{4}$ S. Kim ${ }^{1,2} .{ }^{1}$ Brigham and Women's Hospital, Rheumatology, Inflammation and Immunity, Boston, United States of America; ${ }^{2}$ Brigham and Women's Hospital, Pharmacoepidemiology and Pharmacoeconomics, Boston, United States of America; ${ }^{3}$ F. Hoffmann-La Roche Ltd., Global Medical Affairs - Immunology, Basel, Switzerland: ${ }^{4}$ Genentech, Personalized Healthcare Data Science, South San Francisco, United States of America

Background: Giant cell arteritis (GCA) afflicts older adults, who may have ageand comorbidity-related risks for infection, and is treated with glucocorticoids and other immunosuppressants that might increase the risk of serious infections. Objectives: To examine GCA treatment patterns and rates of serious infections in two real-world cohorts in the U.S.

Methods: Using claims data from two U.S. health insurance databases, Medicare (public, 2007-2017) and MarketScan (commercial, 2015-2019), we selected a cohort of patients with GCA based on a validated claims-based algorithm requiring $\geq 2$ diagnosis codes for GCA plus dispensing of high-dose oral glucocorticoid (PPV 84.8\%) [1]. The Medicare cohort included Medicare enrollees aged $\geq 65$ years with GCA who were treated at a large Massachusetts-based healthcare system; the MarketScan cohort included a nationwide sample of GCA patients aged $\geq 50$ years. GCA index date was the date of $1^{\text {st }}$ glucocorticoid prescription. We assessed baseline comorbidities in the year prior to index date. Immunosuppressants and prophylactic antibiotics dispensed within 30 days of index date were recorded. Influenza vaccine administration in the year after index date was identified. We calculated the incidence rate of serious infections, defined as infections requiring hospitalization, after index date through end of cohort follow-up (12/31/17 in Medicare; 12/31/2019 in MarketScan), disenrollment, or death.

Results: The Medicare cohort included 734 patients, 28\% male, mean age 77.1 (SD 7.4); the MarketScan cohort included 1022 patients, $30 \%$ male, mean age 68.4 (SD 10.9). The most common comorbidity was hypertension $(80 \%$ Medicare; $72 \%$ MarketScan) followed by hyperlipidemia, cancer, coronary artery disease, and diabetes (Table 1). High-dose prednisone was the most common initial treatment; a small percentage received tocilizumab within 30 days of index date. Prophylaxis against pneumocystis pneumonia was similar in Medicare $(13 \%)$ and MarketScan cohorts (10\%). Influenza vaccination was more common in the Medicare (56\%) than MarketScan (22\%) cohort in the year after GCA index date. During the mean follow-up time of 2.6 (SD 2.5) years in Medicare and 1.5 (SD 0.9) years in MarketScan, $27.9 \%$ of the Medicare and $7.2 \%$ of MarketScan patients developed serious infections: incidence rate per 100 person-years $=$ $10.7(95 \% \mathrm{Cl} 9.3,12.2)$ in Medicare and $6.3(95 \% \mathrm{Cl} 5.0,7.9)$ in MarketScan. Conclusion: In these 2 real-world GCA cohorts in the US, over $25 \%$ of Medicare and $7 \%$ of MarketScan patients developed serious infection during follow-up. The incidence rate of serious infection was similar to ANCA-associated vasculitis [2] Use of prophylactic antibiotics and influenza vaccination was suboptimal among GCA patients.

REFERENCES:

[1] Lee H, et al. ACR Open Rheum 2020 (in press).

[2] Rathmann J, et al. Rheumatology 2020; doi: 10.1093/rheumatology/keaa699.

Table 1. Comorbidities, medication use, and infection rates in GCA cohorts

\begin{tabular}{lcc}
\hline & $\begin{array}{c}\text { Medicare cohort } \\
(\mathbf{n}=734)\end{array}$ & $\begin{array}{c}\text { MarketScan } \\
\text { cohort (n=1022) }\end{array}$ \\
\hline Baseline comorbidities & & \\
Hypertension & $80 \%$ & $72 \%$ \\
Hyperlipidemia & $71 \%$ & $61 \%$ \\
Cancer & $38 \%$ & $24 \%$ \\
Coronary artery disease & $34 \%$ & $25 \%$ \\
Diabetes & $34 \%$ & $31 \%$ \\
No. rheumatology visits, mean (SD) & $1.4(2.2)$ & $0.8(1.7)$ \\
Medications within 30 days of index date & $87 \%$ & $91 \%$ \\
Prednisone maximum dose $\geq 60$ mg daily & $<2 \%$ & $5 \%$ \\
Tocilizumab IV or SC & $3 \%$ & $4 \%$ \\
Methotrexate & $13 \%$ & $10 \%$ \\
Bactrim, atovaquone, or dapsone & & $22 \%$ \\
Vaccines in the year after index date & $56 \%$ & $6.3(5.0,7.9)$ \\
Influenza vaccine & $10.7(9.3,12.2)$ & \\
Serious infection incidence rate (95\% Cl) per 100 & & \\
$\quad$ person-years & & \\
\hline
\end{tabular}

Disclosure of Interests: Sara Tedeschi: None declared, Yinzhu Jin: None declared, Seanna Vine: None declared, Hemin Lee: None declared, Attila Pethoe-Schramm Employee of: F. Hoffmann-La Roche, Vincent Yau Employee of: F. Hoffmann-La Roche/Genentech, Seoyoung Kim Grant/research support from: Roche, Pfizer, AbbVie and Bristol-Myers Squibb

DOI: 10.1136/annrheumdis-2021-eular.561

\section{POS0799 THE EFFICACY AND SAFETY OF TOCILIZUMAB IN PATIENTS WITH GIANT CELL ARTERITIS: A SYSTEMATIC REVIEW AND META-ANALYSIS}

M. Koster ${ }^{1}$, K. J. Warrington ${ }^{1}$, J. Han ${ }^{2}$, S. Mohan ${ }^{3} .{ }^{1}$ Mayo Clinic, Division of Rheumatology, Rochester, United States of America; ${ }^{2}$ Genentech, Inc., Biometrics, South San Francisco, United States of America; ${ }^{3}$ Genentech, Inc. Immunology, South San Francisco, United States of America

Background: Tocilizumab (TCZ) has been proven to be safe and effective for the treatment of giant cell arteritis (GCA) in 2 randomized controlled trials; however, data from additional types of studies provide valuable information related to the treatment of GCA with TCZ

Objectives: To review and analyze efficacy and safety data for TCZ in GCA based on peer-reviewed publications to date.

Methods: A systematic literature review was conducted according to the PRISMA guidelines. Publications were retrieved from the MEDLINE, Embase, Cochrane, Scopus and Web of Science databases. Publications of clinical trials and retrospective or prospective observational studies (April 11, 2005-October 8,2019 ) including patients with GCA (classified based on ACR criteria and/or positive biopsy vs imaging) treated with TCZ and reporting a measure of efficacy were eligible for inclusion. Extracted data included year of publication, year(s) when the study was conducted, number of patients with GCA, method of GCA diagnosis, age and sex, TCZ treatment details (dose, route of administration, frequency, duration), clinical outcome (remission, relapse), serious adverse events 
(SAEs) following treatment with TCZ, corticosteroid dose before and following TCZ initiation and imaging data following TCZ treatment. Results are presented for the studies (unweighted) and as the weighted population mean. Unweighted mean proportions were calculated as the average of the proportions reported from each study; unweighted means were calculated by computing the mean of individual reported study means. The weighted population proportion was estimated by calculating the total number of patients achieving an outcome and dividing by the total number of patients in all of the studies. The weighted population mean was equivalent to the sum of the individual patient's outcome values divided by the total number of patients in all of the studies.

Results: The search retrieved 664 references; 55 full-text articles were reviewed for eligibility, and 36 studies were included in the meta-analysis (Figure 1); the once-weekly and every-2-weeks subcutaneous (SC) TCZ arms of the GiACTA trial were counted as separate studies. A total of 519 patients were included. The median (IQR) duration of treatment with intravenous and SC TCZ was 26.0 (20.0-37.3) and 52.0 (26.0-52.0) weeks, respectively, across all studies in the unweighted analysis and 25.8 (20.8-41.9) and 38.9 (32.4-45.5) weeks in the weighted analysis. The mean (SE) proportion of patients achieving investigator-defined remission at the end of the study was $86.3 \%(4.3 \%)$ and $79.3 \%$ $(6.0 \%)$ in the unweighted and weighted analyses, respectively (Table 1$)$. The mean (SE) proportion of patients who relapsed while receiving TCZ was $2.6 \%$ $(1.3 \%)$ and $12.0 \%(4.5 \%)$ in the unweighted and weighted analyses, respectively. The median prednisone dose at the end of the study was $<5 \mathrm{mg} / \mathrm{day}$, and the mean proportion of patients with SAEs after TCZ initiation was $\approx 14.0 \%$. Conclusion: A high proportion of patients with GCA treated with TCZ were in investigator-defined remission at the end of the study across all studies analyzed. These meta-analysis findings add to the evidence of the efficacy and safety of TCZ in GCA.

Figure 1. Study Types Included in Meta-Analysis

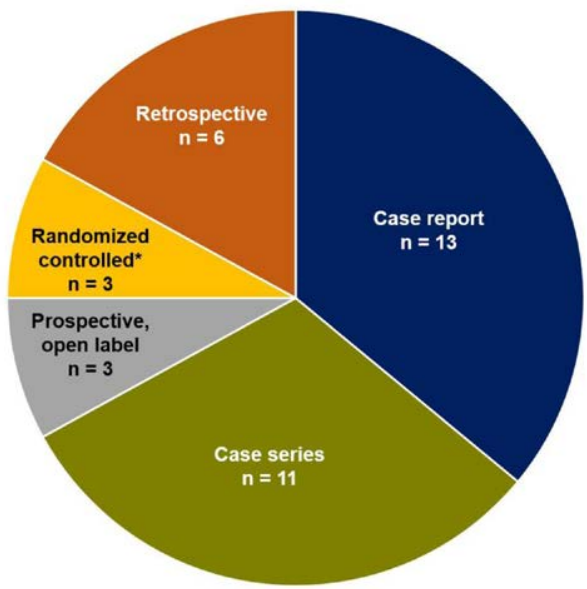

*The subcutaneous TCZ once-weekly and every-2-weeks treatment arms of the GiACTA trial were counted as separate studies.

Table 1. Summary of Remission, Relapse and Adverse Events

\begin{tabular}{|c|c|c|}
\hline Mean (SE) $[95 \% \mathrm{Cl}]$ & $\begin{array}{c}\text { Across GCA Studies; } \\
\text { Unweighted } \\
\text { (n= } 36 \text { studies) }\end{array}$ & $\begin{array}{c}\text { Weighted } \\
\text { Population Mean } \\
\text { ( } n=519 \text { patients) }\end{array}$ \\
\hline \multirow{3}{*}{$\begin{array}{l}\text { Percentage of patients in investigator-defined } \\
\text { remission at the end of the study }\end{array}$} & $\mathrm{n}=35$ & $\mathrm{n}=411$ \\
\hline & $86.3(4.3)$ & $79.3(6.0)$ \\
\hline & [ 77.6 to 94.9 ] & [67.2 to 91.4$]$ \\
\hline \multirow{3}{*}{$\begin{array}{l}\text { Percentage of patients who relapsed while } \\
\text { receiving TCZ }\end{array}$} & $n=31$ & $\mathrm{n}=39$ \\
\hline & $2.6(1.3)$ & $12.0(4.5)$ \\
\hline & {$[-0.18$ to 5.3$]$} & [2.8 to 21.2$]$ \\
\hline \multirow{3}{*}{$\begin{array}{l}\text { Percentage of patients who relapsed after TCZ } \\
\text { discontinuation }\end{array}$} & $n=20$ & $\mathrm{n}=41$ \\
\hline & $26.4(7.8)$ & $14.8(5.8)$ \\
\hline & [10.1 to 42.7$]$ & [2.7 to 26.9 ] \\
\hline \multirow{2}{*}{$\begin{array}{l}\text { Percentage of patients receiving no steroids at } \\
\text { the end of follow-up }\end{array}$} & $n=31$ & $n=170$ \\
\hline & $\begin{array}{c}41.8(6.8) \\
{[27.8 \text { to } 55.8]}\end{array}$ & $\begin{array}{c}49.4(8.1) \\
{[32.8 \text { to } 66.0)}\end{array}$ \\
\hline \multirow{2}{*}{$\begin{array}{l}\text { Percentage of patients with SAEs after TCZ } \\
\text { initiation }\end{array}$} & $\mathrm{n}=35$ & $\mathrm{n}=72$ \\
\hline & $\begin{array}{c}14.0(4.1) \\
{[5.5 \text { to } 22.4]}\end{array}$ & $\begin{array}{c}14.3(1.3) \\
{[11.7 \text { to } 17.0]}\end{array}$ \\
\hline
\end{tabular}

Acknowledgements: This study was sponsored by Genentech, Inc. Support for third-party writing assistance, furnished by Health Interactions, Inc., was provided by Genentech, Inc.

Disclosure of Interests: Matthew Koster: None declared, Kenneth J Warrington Grant/research support from: Lilly and Kiniksa.(clinical trial support), Jian Han Shareholder of: Genentech, Inc., Employee of: Genentech, Inc., Shalini Mohan Shareholder of: Genentech, Inc., Employee of: Genentech, Inc. DOI: 10.1136/annrheumdis-2021-eular.600

\section{\begin{tabular}{|l|l}
\hline POS0800 VISUAL ISCHEMIA DURING RELAPSE AND \\
\hline
\end{tabular} FOLLOW-UP OF GIANT CELL ARTERITIS: A SYSTEMATIC REVIEW}

K. Bugdayli ${ }^{1}$, P. Ungprasert ${ }^{2}$, K. J. Warrington ${ }^{3}$, M. Koster ${ }^{3} .{ }^{1}$ Case Western Reserve University School of Medicine, Internal Medicine, Cleveland, United States of America; ${ }^{2}$ Cleveland Clinic Main Campus, Rheumatology, Cleveland, United States of America: ${ }^{3}$ Mayo Clinic College of Medicine and Science, Rheumatology, Rochester, United States of America

Background: Visual ischemia $(\mathrm{VI})$ is one of the most feared complications in giant cell arteritis (GCA). While the frequencies of VI development at or near diagnosis are better studied, limited information is available regarding the frequency of $\mathrm{VI}$ during relapse.

Objectives: The purpose of this study was to characterize the frequency of visual ischemia $(\mathrm{VI})$ as a manifestation of relapse or during follow-up in patients with GCA through performance of a systematic literature review.

Methods: Potentially eligible studies were identified from Medline and EMBASE databases from inception to November 31, 2019 using a search strategy that comprised of terms for "giant cell arteritis," "temporal arteritis," or "Horton's disease," with "relapse," "recurrence," "flare," "outcome," 'follow-up," or "prognosis." VI was defined as transient or permanent, full or partial, monocular or binocular visual field loss. VI occurring within 4 wks of GCA diagnosis was considered due to active disease and not included as a relapse event. Inclusion criteria used: (1) original research reported in English, (2) GCA definition provided, (3) VI outcome described as one of the following: (a) relapse rate/frequency denoting the presence or absence of $\mathrm{VI}$, or (b) absolute number of VI events ( $>4$ weeks after GCA diagnosis) even if total cohort relapse rate/frequency was not provided. In order to reduce bias from under-reporting of negative results, studies that reported relapse rates/frequencies with accompanying relapse characteristics but did not provide initial detail regarding the presence/absence of VI were also identified. In such circumstances, the primary authors were directly contacted for patient-level data regarding $\mathrm{VI}$ and these studies were included in the final analysis if such data were available and provided.

Results: A total of 913 unique articles were identified and underwent screening Among these, 148 articles underwent independent full-text review by two physicians (K.B. and M.J.K). 33 articles met full inclusion criteria and an additional 21 articles included data on relapse but did not report $\mathrm{VI}$ patient data in the publication. Responses were received from authors of 11 of these 21 studies allowing for inclusion. 44 studies accounting for 3,649 patients with GCA were identified. Average percentage of baseline VI was $19 \%$ (range 0-66\%). The average length of follow-up was 3.4 years (range 0.4 to 8.7 ). VI developing $>4$ weeks after GCA diagnosis was recorded in a total of 53 patients $(1.5 \%)$.

Study-defined relapses were reported in 36 studies. A total of 1,215 patients with at least one or more relapses were recorded among 2,592 patients under observation (47\%). Among these 36 studies, VI occurred in 37 patients (3.0\%) with at least one study defined relapse event.

Comparing trial design, retrospective studies $(n=25)$ reported 27 of $2,718(1 \%)$ patients developed VI during follow-up whereas 19 of $541(3.5 \%)$ patients in randomized controlled trials $(n=8)$ developed VI during the trial or post-trial follow-up. Conclusion: This report outlines the first systematic review evaluating $\mathrm{VI}$ as a manifestation of relapse and during follow-up in GCA. Overall, $\mathrm{VI}>4$ weeks after GCA diagnosis is uncommon (1.5\%) but is noted in up to $3 \%$ of patients with at least one relapse event. Frequencies of reported VI were 3.5 times higher in randomized controlled trials compared to retrospective studies.

Disclosure of Interests: Kubra Bugdayli: None declared, Patompong Ungprasert: None declared, Kenneth J Warrington Grant/research support from: Financial support for research from Kiniksa, Eli Lilly, Matthew Koster: None declared DOI: 10.1136/annrheumdis-2021-eular.697

\section{POS0801 VASCULITIS IN PATIENTS WITH SARCOIDOSIS: A SINGLE-INSTITUTION CASE SERIES OF 17 PATIENTS}

A. Kimbrough ${ }^{1}$, K. J. Warrington ${ }^{2}$, H. Langenfeld ${ }^{3}$, C. S. Crowson ${ }^{2,3}$ E. Carmona ${ }^{4}$, A. Virata ${ }^{5}$, M. Koster ${ }^{2} .{ }^{1}$ Mayo Clinic College of Medicine and Science, Internal Medicine, Rochester, United States of America; ${ }^{2}$ Mayo Clinic College of Medicine and Science, Rheumatology, Rochester, United States of America; ${ }^{3}$ Mayo Clinic School of Health Sciences, Bioinformatics and Statistics, Rochester, United States of America: ${ }^{4}$ Mayo Clinic College of Medicine and Science, Pulmonology and Critical Care Medicine, Rochester, United States of America; ${ }^{5}$ Mayo Clinic College of Medicine and Science, Pathology, Rochester, United States of America 